\title{
НОВАЯ ДЕМОГРАФИЧЕСКАЯ ПОЛИТИКА В КИТАЕ: «ОДНА СЕМЬЯ - ДВА РЕБЕНКА»
}

\author{
ЮЛИЯ КУПРИЯНОВА, АННА ЯНИШЕВСКАЯ
}

\begin{abstract}
В статье рассматриваются особенности введения и реализации новой демографической политики 8 Китае «одна семья - два ребенка». Новая политика направлена на разрешение существуюших серьезных демографических проблем в китайском обществе, вызванных последовательным проведением в течение 35 лет кампании по ограничению рождаемости «одна семья-один ребенок». Рассматриваются основные демографические итоги предыдущих лет, отношение к вопросу рождения второго ребенка в Китае, изменения в политике по контролю рождаемости и взаимосвязь этих изменений с демографическими показателями, а также особенности статистических данных, предоставляемых различными ведомствами Китая, на основании которых происходит учет численности населения и показателей рождаемости. На основе данных официальной статистики и опросов населения за последние годы даются количественные и качественные характеристики рождаемости и репродуктивных установок современного общества. Анализ существующих данных, взятых из различных источников, позволяет отметить устойчивое падение суммарного коэффициента рождаемости, снижение естественного прироста населения, уменьшение показателей желаемого и планируемого числа детей в семье, а также распространение добровольного отказа от рождения детей в крупных городах страны. Подобные тенденции позволяют предположить, что власти Китая несколько запоздали с либерализацией политики планирования семьи. В статье выделены основные факторы, которые будут оказывать влияние на прирост населения Китая в ближайшие десятилетия, и сделан вывод о завышенности прогнозов роста населения страны, сделанных офищиальными ведомствами КНР.
\end{abstract}

Ключевые слова: политика ограничения рождаемости в КНР, одна семья - два ребенка, бездетность, население Китая, репродуктивное поведение, малодетность.

\section{ВВЕДЕНИЕ}

В конце 2015 г. в Китае произошло важное событие, вызвавшее значительный общественный резонанс: было принято решение о полной отмене демографической политики «одна семья - один ребенок», которая проводилась в стране более 35 лет и использовала экономические и внеэкономические меры для ограничения рождения вторых детей в семьях. С 1 января 2016 г. правительство разрешило всем семьям иметь двух детей, была провозглашена линия «одна семья - два ребенка». Требования о необходимости смягчения называемой на Западе «негуманной» политики планирования семьи звучали уже давно, но столкнувшись с замедлением экономического роста, сокращением трудоспособного населения, незрелостью системы пенсионного обеспечения, проблемой старения и серьезного полового дисбаланса, руководство решилось на переход к новой демографической политике только к началу реализации 13-го пятилетнего плана социально-экономического развития (2016-2020 гг.).

ЮЛИЯ АНДРЕЕВНА КУПРИЯНОВА (yukupriyanova@hse.ru), НАЦИОНАЛЬНЫЙ ИССЛЕДОВАТЕЛЬСКИЙ УНИВЕРСИТЕТ «ВЫСШАЯ ШКОЛА ЭКОНОМИКИ», РОССИЯ.

АННА ИваНОвНА ЯНИшЕВСКАЯ (ayanishevskaya@hse.ru), НАЦИОНАЛЬНЫЙ ИССЛЕДОВАТЕЛЬСКИЙ УНИВЕРСИТЕТ «ВЫСШАЯ ШКОЛА ЭКОНОМИКИ», РОССИЯ.

СТАТЬЯ ПОСТУПИЛА В РЕДАКЦИЮ В МАРТЕ 2017 Г. 
Сразу после принятия важного решения в Китае и за его пределами развернулась дискуссия: не опоздала ли КНР с корректировкой курса? Будет ли достигнут ожидаемый эффект? Захотят ли миллионы однодетных китаянок завести второго ребенка и тем самым в среднесрочной перспективе простимулировать экономическое развитие страны [Кислова, Буяров 2016: 347]?

В данной статье мы пытаемся ответить на вопрос: будут ли достигнуты желаемые демографические показатели в китайском обществе к 2020 и к 2030 г. соответственно. Для этого нам необходимо рассмотреть существующие предпосылки, которые будут определять рождаемость в ближайшие годы, дать характеристику репродуктивного поведения современного китайского общества, а именно той его части, на которую делается основной акцент в новых демографических преобразованиях КНР в 2016 г.

\section{ДЕМОГРАФИЧЕСКИЕ ИТОГИ 2016 ГОДА}

По завершении первого года после введения новой демографической политики «одна семья - два ребенка» соответствующие ведомства Китая поспешили отчитаться о положительных результатах: рождаемость выросла. Однако, анализируя данные, представляемые центральными властями КНР, стоит учитывать, что они могут не соответствовать действительности. Даже само правительство признает, что существует проблема приписывания нужных чисел в регионах, что влечет за собой искажение общей картины, получаемой по стране в целом. Поэтому для полноценного анализа необходимо исследовать информацию из разных источников.

По данным Исследовательского центра демографии и развития Китая, опубликованным осенью 2016 г., среднемесячное число новорожденных с 1 января 2016 г. составляло около 1 млн 290 тыс., что на 90000 ниже данных за аналогичный период 2015 г. Прогнозировалось снижение годовых показателей, общее число рожденных в 2016 г. должно было составить всего 15,5 млн ${ }^{1}$. Подобные оценки не совпадали с целями, поставленными правительством на пятилетний план развития. По итогам первого года введения новой политики «одна семья - два ребенка» официальные ведомства КНР представили общественности более позитивные результаты. По информации Государственного статистического управления (ГСУ) КНР, согласно данным выборочного обследования 1\% населения, в 2016 г. в Китае родилось 17,86 млн детей ${ }^{2}$. По информации Государственного комитета по делам здравоохранения и планового деторождения (далее Государственный комитет), число детей, рожденных в роддомах, составило 18,46 млн ${ }^{3}$.

\footnotetext{
${ }^{1}$ Sheng huo busheng ertai, women youle xuanze de quanli [Рожать ли второго ребенка, у нас появилось право выбора]. URL: http://www.bjnews.com.cn/news/2016/10/18/420220.html (дата обращения: 10.04.2017).

2 2016: A good start for China's economy during the 13th five-year plan period. National bureau of statistics of China. URL: http://www.stats.gov.cn/enGLISH/PressRelease/201701/t20170120_1455922.html (дата обращения: 15.01.2017).

${ }^{3}$ Guojia weisheng jishengwei: 2016 nian quanguo chusheng renkou erhai ji yishang zhan biyu sicheng [Государственный комитет по делам здравоохранения и планового деторождения: в 2016 году количество рожденных вторых детей составило свыше 40\%]. URL: http://www.gov.cn/xinwen/2017-

01/23/content_5162367.htm (дата обращения 02.03.2017).
} 
Таким образом, цифры официальных ведомств однозначно говорят о росте показателей рождаемости по сравнению с предыдущим годом.

Новая политика оказала влияние и на показатели естественного прироста населения: в 2014 г. он равнялся 0,49\% [Киреев 2015: 15], а в 2016 г. - 0,586\% ${ }^{4}$. Однако данные других источников указывают на более низкий естественный прирост $(0,53 \%)^{5}$. Даже если опираться на официальную статистику КНР, стоит сказать, что итоги первого года введения новой политики не полностью оправдали ожидания правительства. План развития страны на тринадцатую пятилетку предусматривает увеличение общей численности населения за пять лет на 45 млн человек, т.е. примерно до 1 млрд 427 млн. За 2016 г. население увеличилось на 8 млн 090 тыс. человек ${ }^{6}$, до запланированных 9 млн ежегодного прироста не хватило почти миллиона.

Как уже говорилось, верификация текущих показателей рождаемости в Китае представляется сложной задачей. К примеру, авторы статьи о репродуктивном поведении китайских семей, анализируя информацию о демографической ситуации в КНР в сообщениях 19 китайских авторов, выделили 31 способ подсчета суммарного коэффициента рождаемости (далее СКР). Исходя из полученных данных за один и тот же период, авторы получили показатели от 1,22 до 2,3 [Basten, Gu 2013b: 11]. Они также сделали вывод о том, что ряд китайских исследований (к примеру, опросы 1988, 1992, 1997 , 2001 и 2006 г., проведенные Государственным статистическим управлением), основаны на неподтвержденной информации. В 2006 г. ГСУ опубликовало данные, где СКР составил всего 1,6. Однако в Государственном комитете неохотно признавали падение и утверждали, что этот показатель все еще составляет около 1,8 [Basten, Gu 2013b 12-13], что является наглядным примером расхождения данных, представляемых государственными ведомствами КНР. Некоторые ученые утверждают, что различия в учете рождаемости могут достигать 20\%, что в прогнозируемой численности населения нельзя считать незначительным расхождением [Ван 2015: 305].

Уже много лет подряд в Китае оказывается тревожно низким суммарный коэффициент рождаемости, который для оптимального уровня простого воспроизводства населения должен составлять не менее 2,1 [Киреев 2015: 15]. Согласно данным 2005 г., более 90\% граждан КНР проживало в провинциях, где СКР составлял 1,0-1,3. Крайне низкий коэффициент рождаемости $(<0,9)$ был зафиксирован в Пекине, Шанхае, Тяньцзине и других крупных городах [Basten, Gu 2013b: 14]. По данным переписи населения 2010 г., СКР в крупных городах был 0,88 при среднекитайском в 1,18. По итогам выборочной

\footnotetext{
${ }^{4}$ 2016: A good start for China's economy during the 13th five-year plan period. National bureau of statistics of China. URL: http://www.stats.gov.cn/enGLISH/PressRelease/201701/t20170120_1455922.html (дата обращения: 15.01.2017).

${ }^{5}$ Население Китая. URL: http://countrymeters.info/ru/CHina (дата обращения: 25.03.2017).

6 2016: A good start for China's economy during the 13th five-year plan period. National bureau of statistics of China. URL: http://www.stats.gov.cn/enGLISH/PressRelease/201701/t20170120_1455922.html (дата обращения: 15.03.2016).
} 
переписи населения за 2015 г. СКР среди женщин детородного возраста составил всего $1,047^{7}$.

\section{РОЖДЕНИЕ ВТОРЫХ ДЕТЕЙ В КИТАЙСКИХ СЕМЬЯХ}

С 1984 г. в ряде провинций КНР начались первые послабления в политике ограничения рождаемости «одна семья - один ребенок», что позволило части деревенских и городских семей завести второго ребенка без уплаты социальных штрафов и других «санкций» со стороны официальных властей. На первом этапе особые меры касались только тех семей, где мать и отец являлись единственными детьми в своих семьях, в СМИ они получили название shuāngdú liănghái (双独两孩). В конце 2013 г. ЦК КПК принял новое постановление, получившее название dāndú èrhái (单独二孩) - «один родительединственный ребенок - двое детей». Новая мера позволила китайским семьям, в которых хотя бы один из родителей является единственным ребенком, иметь двоих детей. По официальным данным, за первые 9 месяцев введения данной политики в 2014 г. из 11 млн супружеских пар, которым было разрешено без каких-либо ограничительных мер завести второго ребенка, только 800 тыс. обратились в соответствующие ведомства для оформления разрешения на рождение второго ребенка, что составило всего 7\% [Basten, $\mathrm{Gu} 2013 \mathrm{a}]$.

На данный момент в Китае 90 млн китаянок детородного возраста соответствуют условиям новой политики 2016 г. «одна семья - два ребенка». Однако 60\% этих женщин уже старше 35 лет, половина старше 40 лет $^{8}$. Сама вероятность родить для женщин данного возраста, особенно с учетом плохой экологической обстановки во многих городах страны, невелика. Кроме того, многие ученые отмечают возможные риски для здоровья новорожденных. Помимо проблемы «старородящих матерей» существует и проблема уменьшения числа рожениц в КНР. Представитель Государственного комитета Ян Вэньчжуан говорит о том, что за период 12-го пятилетнего плана (2011-2015 гг.) число женщин детородного возраста в стране ежегодно снижалось на 3,5 млн человек, а к моменту наступления 13-й пятилетки эта цифра достигла 5 млн 9 . То есть в перспективе стоит ожидать снижения общего числа рождений, и замедлить этот процесс может только увеличение коэффициента рождаемости, что напрямую связано с успешностью имплементации новой демографической политики «одна семья - два ребенка».

Итак, захотят ли молодые китаянки рожать вторых детей в современных социальноэкономических условиях? До введения политики dāndú èrhái процент рождений вторых

\footnotetext{
${ }^{7} 2015$ nian Zhongguo zonghe shengyulv wei 1.047 zhuanjia cheng dide chuhu yiwai [Специалисты отмечают, что в Китае неожиданно низкий суммарный коэффициент рождаемости, который в 2015 году составил 1,047]. URL: Retrieved: http://finance.sina.com.cn/roll/2016-10-28/doc-ifxxfuff7065330.shtml (дата обращения: 29.03.2017).

8 "Shisanwu" jisheng guihua: nianjun renkou zenmezhang 900 wan 2016 nian shangwei "dabiao" [План по контролю рождаемости в 13-й пятилетке: среднегодовой прирост населения в 2016 году составил 9 млн человек, что все еще не достигает необходимых показателей]. URL: http://m.21jingji.com/article/20170208/3dcf3772f2aed67561a1ca105ae60d7a.html (дата обращения: 22.03.2017). ${ }^{9}$ Там же.
} 
детей в КНР составлял около $30 \%{ }^{10}$, в 2014-15 гг. этот показатель постоянно рос, и в 2016 г. доля рождений вторых детей составила уже $45 \%{ }^{11}$. Очевидно, что смягчение ограничений в 2013 г. принесло определенные плоды. Однако среди части китайского населения бытует мнение, что полная отмена политики «одна семья - один ребенок» уже не способна принести каких-либо улучшений демографической ситуации в краткосрочной перспективе: «собиравшиеся рожать - родят, кто не хотел рожать - тот по-прежнему не будет рожать» ${ }^{12}$. К тому же, стоит ожидать, что к 2018 г. наступит конец «эйфории» от принятия новой политики «двоих детей» и мы уже не увидим рекордные показатели рождений у матерей старше 35 лет.

На просторах китайского Интернета, в соцсетях и различных блогах проводилось немало опросов на тему, планируют ли семьи с одним ребенком рождение второго. По данным одного из таких опросов, $82 \%$ семей в силу различных причин не готовы к рождению второго ребенка [Гулева 2016: 39-40]. Специалисты считают, что улучшение экономической ситуации в стране в целом не влияет на решение рожать ребенка, особенно если число детей в семье соответствует потребностям супругов. Прибавление в семье возможно тогда, когда эта потребность не удовлетворена, тогда улучшение условий жизни может оказать влияние на конечное решение о рождении нового ребенка, да и то не всегда. В случае с КНР стоит говорить о том, что желаемое число детей в городских семьях существенно ниже уровня, разрешенного властями, соответственно новая демографическая политика вряд ли даст заметный эффект. Потребуется не одно десятилетие, чтобы показатель желаемого числа детей возрос.

\section{МОДЕЛЬ РЕПРОДУКТИВНОГО ПОВЕДЕНИЯ СОВРЕМЕННОГО КИТАЙСКОГО ОБЩЕСТВА}

Для понимания перспективы новой демографической политики необходимо уделить внимание репродуктивным установкам нынешней китайской молодежи, что поможет дать ответ на вопрос: оправдаются ли демографические прогнозы китайских властей на ближайшие 10-15 лет. В данном исследовании мы рассматриваем не все население КНР в целом, а репродуктивные установки определенной группы. В общем мы можем говорить о том, что объектом изучения являются горожане, а также часть сельских трудовых мигрантов, проживающих в городе в течение длительного времени. Во-первых, именно

\footnotetext{
${ }^{10}$ Erhai shengyu yuyuan diaocha: "Dusheng bama", er san xian chengshi jiating yiyuan genggao [Опрос о намерении родить второго ребенка: «мать и отец, являющиеся единственными детьми в семье» - желание рожать в семьях городов второй и третьей линии намного выше]. URL: http://www.21jingji.com/2017/223/wOMDEzNzlfMTQwMzEwOA.html (дата обращения: 12.03.2017).

${ }^{11}$ Guojia weisheng jishengwei: 2016 nian quanguo chusheng renkou erhai ji yishang zhan biyu sicheng [Государственный комитет по делам здравоохранения и планового деторождения: в 2016 году количество рожденных вторых детей составило свыше 40\%]. URL: http://www.gov.cn/xinwen/2017-

01/23/content_5162367.htm (дата обращения: 02.03.2017).

${ }^{12}$ Zhe yi dai ren yijing meile sheng ertai de yongqi [У нынешнего поколения уже нет решимости рожать второго ребенка]. URL: https://commondatastorage.googleapis.com/letscorp_archive/archives/97064 (дата обращения: 01.03.2017).
} 
жители городов являются объектами новой политики «одна семья - два ребенка», так как жителям деревень и раньше было позволено иметь двоих детей при соблюдении ряда условий (например, если первым ребенком была девочка или ребенок рождался инвалидом). Во-вторых, в условиях активного процесса урбанизации, который идет в Китае не одно десятилетие, городское население уже составило больше половины всех жителей, а именно 57,35\% (2016 г.) $)^{13}$, и в ближайшей перспективе будет расти и дальше. По ряду прогнозов к 2030 г. урбанизация КНР должна достигнуть 70\%, а число горожан превысить 1 млрд [Островский 2013: 41].

Если говорить о репродуктивном поведении исследуемой группы, то оно характеризуется как малодетное (1-2 ребенка в семье). Подобная модель поведения в китайском обществе определяется как общемировыми тенденциями, так и реалиями демографической политики властей КНР за последние 35 лет. В целом в большинстве стран мира молодежь предпочитает семьи меньшего размера, чем люди старшего возраста. Эти данные подтверждаются данными исследования рождаемости, проведенного организацией «Евробарометр» [Соботка, Лутц 2011]. Данный феномен связан с фактическим уменьшением размера семьи. Кроме того, свое влияние оказывают особенности второго демографического перехода. Молодые люди хотят рожать меньше, чем поколение их родителей. Согласно исследованиям, в Нанкине среднее идеальное число детей в семье составляет 1,2 для тех, кому до 30 лет, и 1,3 для тех, кому за 30 [Basten, Gu 2013b: 25-26]. Данные опроса, проведенного Государственным комитетом в 2001 г., показывают, что среднее идеальное число детей у замужних женщин в возрасте от 20 до 49 лет в городских районах составляло 1,46 против 1,81 в сельских районах. В экономически развитых районах данный показатель составлял 1,39, в среднеразвитых - 1,66, а в отстающих - 1,96. Более половины женщин в возрасте от 20 до 49 лет, проживающих в городах, хотели одного ребенка [Basten, Gu 2013b: 18]. То есть мы можем видеть, что репродуктивные установки во многом обусловлены как возрастом индивидуума, там и экономическими условиями, в которых он проживает. Чем моложе возраст и чем выше уровень развития конкретного региона, тем ниже показатель идеального числа детей в семье.

Условия жизни прошлых лет, взросление без братьев и сестер определяют уровень индивидуальной потребности в детях у современной молодежи в Китае. Так как данная потребность является результатом усвоения определенной модели репродуктивного поведения, она не подвержена резкому изменению на протяжении всей жизни поколения. Соответственно, невозможно за счет введения новой демографической политики добиться немедленных результатов. Здесь мы вплотную сталкиваемся с гипотезой Лутца о «ловушке низкой рождаемости», согласно которой, вырастая в окружении малодетных или бездетных семей, новое поколение придерживается аналогичного репродуктивного поведения, предпочитает иметь мало детей или не иметь их совсем [Фахрисламова 2015: 105]. В одном из последних докладов Академии общественных наук КНР (2015 г.) говорится, что СКР в

${ }^{13}$ 2016: A good start for China's economy during the 13th five-year plan period. National bureau of statistics of China. URL: http://www.stats.gov.cn/enGLISH/PressRelease/201701/t20170120_1455922.html (дата обращения: 15.03.2016). 
Китае сейчас составляет 1,4 на женщину, то есть приблизился к общепризнанному тревожному уровню в 1,3 - или «ловушке низкой рождаемости» ${ }^{14}$. Самое тревожное то, что еще ни одна страна не смогла выбраться из этой «ловушки» и вернуться на уровень естественного воспроизводство нации. Согласно концепции Лутца, «ловушка» заключается еще и в том, что в малодетном обществе начинают работать самоусиливающиеся механизмы, которые могут приводить к еще большему снижению рождаемости. Если придерживаться данной идеи, то можно предположить, что поколение китайцев 1980-х и 1990-х годов, которое росло при тотальной политике ограничения рождаемости, в своем репродуктивном поведении будет ориентироваться по-прежнему на однодетную семью, некоторые вообще предпочтут не заводить детей. Поэтому изменения в демографической политике властей не принесут желаемых результатов в ближайшие десятилетия. Только поколение китайцев, родившихся в 10-х годах XXI века, в момент волны либерализации демографической политики, будет отличаться новыми установками в своем репродуктивном поведении. Но пик рождений этой возрастной группы придется только на 2035-2040 гг.

В апреле 2016 г. Центром по изучению демографии и развития Китайского народного университета был проведен опрос под названием «Исследование механизма принятия решения о рождении ребенка в китайских семьях» ${ }^{15}$. В опросе участвовало 6000 женщин в возрасте от 20 до 49 лет из 12 крупных городов 6 провинций КНР: Гуандун, Сычуань, Хубэй, Шаньдун, Чжэцзян, Ляонин. В среднем, показатель идеального числа детей в семье составил 1,75; по сравнению с данными опросов за 2010-13 гг. (1,78-1,8) произошло незначительное падение. При этом только около 30\% опрошенных женщин планируют иметь двоих детей $(24,4 \%$ имеют четкий план с указанием времени рождения второго ребенка; 5,1\% планируют, но не знают, когда точно). Еще 8,9\% женщин не уверены в том, смогут ли они родить второго ребенка.

Согласно результатам, среднее значение планируемого числа детей для женщинматерей одного ребенка в возрасте от 35 до 39 лет и в возрасте от 40 до 49 лет - стремится к 1,22 и 1,09 соответственно. Поэтому при анализе демографического потенциала роста рождаемости для китаянок следует, в первую очередь, опираться на данные по количеству женщин в возрасте до 35 лет, так как вероятность того, что женщины более старшего возраста будут реализовывать свое право на рождение второго ребенка очень низкая.

В декабре 2016 г. был опубликован доклад с результатами опроса населения, организованного совместно Всекитайской федерацией женщин и Пекинским педагогическим университетом. Тема опроса: «Влияние политики «двух детей» на домашнее воспитание» ${ }^{16}$. Опрос проводился в 10 провинциях и городах центрального

\footnotetext{
${ }^{14}$ China close to cow fertility trap. URL: http://www.china.org.cn/video/2015-01/07/content_34495147.htm (дата обращения: 04.03.2017).

${ }^{15}$ Quanmian erhai zhengce beijing xia zhongguo chengshi nvxing de shengyu pianhao yu shengyujihua [Репродуктивные установки и планы женщин в городах КНР на фоне введения политики двоих детей]. URL: http://www.lepp.zju.edu.cn/upload/2017-03/17031521265406.pdf (дата обращения: 07.03.2017).

${ }^{16}$ Quanguo fulian fabu quanmian erhai zhengce dui jiating jiaoyu yingxiang diaocha baogao [Отчет Национальной федерации женщин КНР по итогам исследования влияния политики «одна семья - два ребенка» на
} 
подчинения Китая: Пекин, Шаньдун, Цзянсу, Хэнань, Аньхой, Гуандун, Гуанси, Шэньси, Сычуань; а также в 21 городе (районе). Респонденты - родители, имеющие детей от 0 до 15 лет. Цели опроса: выявить основные факторы, влияющие на желание родителей заводить второго ребенка. Более половины опрошенных $(53,3 \%)$ не имеют желания заводить второго ребенка. Еще больше подобных респондентов насчитывается в Пекине и восточных провинциях страны: 62,3 и 62,5\% соответственно. В среднем доля желающих родить второго малыша составила лишь 20,5\%, а тех, кто еще не определился - 26,2\%. Меньше всего хотят заводить ребенка жители наиболее развитых районов (жители Пекина и восточных провинций Китая). В этих же районах меньше всего семей, которые уже завели второго ребенка; доля семей, проживающих в городе и имеющих второго ребенка, составляет всего $29,6 \%$.

Обобщая данные проведенных опросов и ряда зарубежных исследований, можно сказать, что во многом результаты оказались схожими. Чуть более половины городских семей не хотят заводить второго ребенка. Намерение иметь двоих детей в семье выражают от 20 до 30\% опрошенных. Оставшиеся 20-30\% либо еще не определились в своих намерениях, либо вообще не хотят иметь детей (около 10\%).

На данном этапе развития Китая бездетность становится все более актуальной темой, а в определенной степени даже не темой, а проблемой. Все больше исследователей с тревогой отмечают рост числа семей dingkè (丁克), что соответствует в русском языке

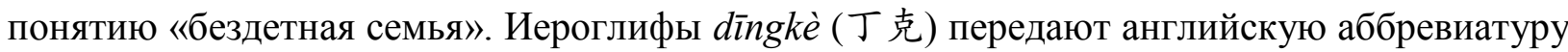
DINK, которая расшифровывается как «double incomes no kids»- двойной доход без детей. Само понятие появилось в Китае еще в 1980-е годы, с момента начала проведения политики ограничения рождаемости. Сейчас сознательный отказ супругов от воспитания детей явление достаточно частое в условиях городской жизни. По данным на 2010 г. 98\% таких семей живут в больших городах Китая, их общее количество составляет около 600 тыс. [Челнокова-Щейка 2013:310]. В Пекине и Шанхае они составляют 10\% всех семейных пар репродуктивного возраста. Согласно данным Китайского общего социального опроса за 2008 г., доля бездетных среди опрошенных горожанок детородного возраста составила 11,5\% [Zhang 2016: 4].

Перенаселенность, экономическая конкуренция, психологическая незрелость, взросление без братьев и сестер - вот лишь немногие факторы, которые приводят к увеличению числа сторонников жизни в стиле DINK. Однако основные причины выбора бездетности связаны с экономическими сложностями, среди них можно назвать дороговизну проживания, рождения и воспитания ребенка в городе. По данным выборочного обследования Шанхайской комиссии по вопросам народонаселения и планирования семьи, опубликованным в 2009 г., для 12000 опрошенных в возрасте от 20 до 45 лет (жители, имеющие местную прописку, а также представители мигрирующего населения, проживающие в Шанхае более полугода), основной причиной отказа от

образование в семье]. URL: http://baby.sina.com.cn/news/2016-12-22/doc-ifxyxury8000532.shtml (дата обращения: 08.03.2017). 
рождения детей в семьях DINK являются слишком высокие расходы на их воспитание ${ }^{17}$. Так, по данным сайта о проблемах материнства, при средних запросах городской семьи воспитание ребенка вплоть до наступления совершеннолетия обходится примерно в 3 млн рублей (более 20000 юаней в год), а если добавить к этому расходы на 4 года обучения в обычном китайском университете, то данная сумма увеличивается еще на 2 млн рублей ${ }^{18}$. При этом, по данным Государственного статистического управления, доход на душу населения в городских домохозяйствах составляет около 280 тыс. рублей (чуть больше 30000 юаней в год), из чего можно сделать вывод о том, что воспитание ребенка весьма дорогостоящее мероприятие для среднестатистической городской семьи [China Statistical Yearbook 2016].

\section{ЗАКЛЮЧЕНИЕ}

Рассмотрев первые итоги введения новой демографической политики правительства Китая, особенности программы ограничения рождаемости, проводимой в стране более 35 лет, а также изучив репродуктивное поведение современных семей, можно сделать вывод, что власти страны явно запоздали с либерализацией политики планирования семьи. Сокращение количества женщин фертильного возраста, снижение показателей планируемого числа детей в семье, распространение семей, добровольно отказывающихся от деторождения - вот те некоторые важные факторы, которые в ближайшие десятилетия будут определять демографическую ситуацию и не позволят КНР выйти из «ловушки низкой рождаемости». На основании проведенного анализа мы можем предположить, что в ближайшие 20-25 лет в Китае сохранится низкий уровень рождаемости, вероятнее всего, суммарный коэффициент рождаемости будет падать, несмотря на введение политики «одна семья - два ребенка». По итогам 13-го пятилетнего плана социально-экономического развития Китай не сможет достигнуть планируемых показателей численности населения в 2020 г. Потребуется корректировка в сторону снижения планируемых темпов роста населения в 14-м пятилетнем плане. Аналогично и среднесрочные прогнозы по демографическим показателям к 2030 г. должны будут подвергнуться изменению.

Столкнувшись с сокращением прироста населения и осознавая важность сохранения как можно большего процента трудоспособного населения, правительство, вероятнее всего, пойдет на введение ряда стимулирующих экономических мер в демографической политике, подталкивая новые пары к рождению двоих детей.

\footnotetext{
172015 nian Zhongguo zonghe shengyulv wei 1.047 zhuanjia cheng dide chuhu yiwai [Специалисты отмечают, что в Китае неожиданно низкий суммарный коэффициент рождаемости, который в 2015 году составил 1,047]. URL: http://finance.sina.com.cn/roll/2016-10-28/doc-ifxxfuff7065330.shtml (дата обращения 29.03.2017).

${ }^{18}$ Bang ni suanyisuan sheng ge ertai yaohua duoshao qian [Помощь в расчете затрат на воспитание второго ребенка]. URL: http://baby.39.net/a/151030/4719370.html (дата обращения: 28.03.2017).
} 


\section{ЛИТЕРАТУРА}

Ван Е. (2015). Демографическая политика Китая в начале XXI века // Настоящее и будущее семьи в меняющемся мире / Под ред. Н. Римашевской. М.: Экон-Информ: 303-310.

Гулева М.А. (2016). Отмена политики «Одна семья - один ребенок» в Китае // Азия и Африка сегодня. 6: 36-40.

Киреев А.А. (2015). Изменения демографической политики Китая // Ученые записки Комсомольского-на-Амуре государственного технического университета. 2(2): 15-17.

Кислова Е.В., Д.В. Буяров (2016). Влияние политики на решение демографических проблем XXI века в Китае // VI международная научно-практическая конференция «Россия и Китай: история и перспективы сотрудничества» (РФ, Благовещенск, 16-18 мая 2016 г.). Благовещенск: Издательство БГПУ: 347-350.

Островский А.В. (2013). Экономика КНР в 2030 году: проблемы и перспективы (как относиться к прогнозу экономического развития КНР, сделанному центром изучения положения в стране университета Цинхуа) // Доклады ИДВ РАН 2012. М.: ФГБУН Институт Дальнего Востока Российской академии наук: 29-50.

Соботка Т., В. Лутц (2011). Коэффициент суммарной рождаемости дает политикам дезориентирующие сигналы: не следует ли отказаться от использования этого показателя? (перевод английского: Sobotka T.,W. Lutz (2010). Misleading policy messages derived from the period TFR: should we stop using it? // Comparative Population Studies. 35(3): 637-664) // Экономический журнал ВШЭ. 4: 444-471. См. также: Демоскоп Weekly. 495-496. URL: http://www.demoscope.ru/weekly/2012/0495/analit01.php

Фахрисламова Р.Т. (2015). Низкая рождаемость: теории и подходы к объяснению // Вестник Южно-Российского государственного технического университета. Серия: Социально-экономические науки. 2: 101-109.

Челнокова-Щейка А.В. (2013). Трансформация семейных ценностей в современном Китае // Знание. Понимание. Умение. 4: 309-314.

Basten S., B. Gu (2013a). Has China fallen into the 'low fertility trap'? // Population: the long view. St.John's College, Oxford (September 2013). URL: https:// http://archive.spi.ox.ac.uk/fileadmin/documents/PDF/131025_Basten_China_Low_Fertility_ Trap.pdf (accessed: 16.03.2017).

Basten S., B. Gu (2013b). Childbearing preferences, reform of family planning restrictions, and the low fertility trap in China // Working Paper. University of Oxford. Department of social policy and intervention. Oxford centre for population research: 61: 43.

China Statistical Yearbook (2016). Compiled by national bureau of statistics of China. URL: http:// http://www.stats.gov.cn/tjsj/ndsj/2016/indexeh.htm (дата обращения: 06.03.2017).

Zhang L. (2016). DINK family: the fashion of the youth? - a cross-national comparative study // A sociological almanac. 7: 442-454. 


\title{
NEW POPULATION POLICY IN CHINA: «ONE FAMILY - TWO CHILDREN»
}

\author{
YULIA KUPRIYANOVA, ANNA YANISHEVSKAYA
}

\begin{abstract}
The article examines the distinctive features of China's introduction and implementation of its new two-child policy, aimed at solving the demographic problems caused by 35 years of consistent execution of its onechild birth control campaign. It looks at the main demographic results of previous years, attitudes to having a second child, changes in birth control policy and the relationship of these changes with demographic indicators, as well as at certain features of the statistics provided by various departments of China on which population size and fertility indicators are based. It gives, based on the data of official statistics and population surveys in recent years, quantitative and qualitative characteristics of fertility and of the reproductive attitudes of modern society. Analysis of existing data taken from various sources makes it possible to note a steady decline in the total fertility rate, a decrease in natural population growth, a decrease in the desired and planned number of children in the family, and the proliferation in major cities of the country of voluntary renunciation of having children. Such trends suggest that the Chinese authorities are somewhat late with the liberalization of family planning policies. The article highlights the main factors that will influence the growth of China's population in the coming decades, and concludes that the country's population growth forecasts made by official departments of the People's Republic of China are too high.
\end{abstract}

Keywords: birth control policy in China, one family - two children, childlessness, population of China, reproductive behavior, nuclear family.

Yulia A. Kupriyanova (yukupriyanova@hse.ru), NATional Research University Higher School of Economics, RUSSIA.

ANNA I. YANishevskaya (ayanishevskaya@ @he.ru), NATIONAL ReSEARCH University Higher SCHOOl OF ECONOMICS, RUSSIA.

DATE RECEIVED: MARCH 2017.

\section{REFERENCES}

Basten S., B. Gu (2013a). Has China fallen into the 'low fertility trap'? // Population: the long view. St.John's College, Oxford (September 2013). URL: https:// http://archive.spi.ox.ac.uk/fileadmin/documents/PDF/131025_Basten_China_Low_Fertility_ Trap.pdf (accessed: 16.03.2017).

Basten S., B. Gu (2013b). Childbearing preferences, reform of family planning restrictions, and the low fertility trap in China // Working Paper. University of Oxford. Department of social policy and intervention. Oxford centre for population research: 61: 43.

Chelnokova-Shhejka A.V. (2013). Transformatsiya semeynykh tsennostey v sovremennom Kitae [The transformation of family values in modern China] // Znanie. Ponimanie. Umenie [Knowledge. Understanding. Skill]. 4: 309-314.

China Statistical Yearbook (2016). Compiled by national bureau of statistics of China. URL: http:// http://www.stats.gov.cn/tjsj/ndsj/2016/indexeh.htm (дата обращения: 06.03.2017).

Fahrislamova R.T. (2015). Nizkaya rozhdaemost': teorii i podkhody k ob"yasneniyu [Low fertility: theories and approaches for explanation] // Vestnik Yuzhno-Rossiyskogo gosudarstvennogo tekhnicheskogo universiteta [Bulletin of the South Russian State technical 
university]. Seriya: Sotsial'no-ekonomicheskie nauki [Series: Socio-economic sciences]. 2: 101-109.

Guleva M.A. (2016). Otmena politiki "Odna sem'ya - odin rebenok" v Kitae [Cancellation of 'One family - one child' policy in China] // Aziya i Afrika segodnya [Asia and Africa today]. 6: $36-40$.

Kireev A.A. (2015). Izmeneniya demograficheskoy politiki Kitaya [The changes in demographic policy of China] // Uchenye zapiski Komsomol'skogo-na-Amure gosudarstvennogo tekhnicheskogo universiteta [Scientific notes of Komsomolsk-on-Amur state technical university]. 2(2): 15-17.

Kislova E.V., D.V. Bujarov (2016). Vliyanie politiki na reshenie demograficheskikh problem XXI veka v Kitae [The impact of politics on the solution of demographic problems of the XXI century in China] // VI mezhdunarodnaya nauchno-prakticheskaya konferentsiya «Rossiya i Kitay: istoriya i perspektivy sotrudnichestva» (Russia, Blagoveshchensk, 16-18 maya 2016 g.) [VI international scientific-practical conference «Russia and China: history and prospects of cooperation» (RF, Blagoveshchensk, 16-18 may, 2016]. Blagoveshhensk: Izdatelstvo BGPU: 347 - 350 .

Ostrovskij A.V. (2013). Ekonomika KNR v 2030 godu: problemy i perspektivy (kak otnosit'sya k prognozu ekonomicheskogo razvitiya KNR, sdelannomu tsentrom izucheniya polozheniya v strane universiteta Tsinkhua) [The chinese economy in 2030: problems and prospects (how to treat the forecast of economic development of China made by the national conditions studies center, Tsinghua university)] // Doklady IDV RAN 2012 [Reports of the RAS IFES 2012]. Moscow: FGBUN Institut Dal'nego Vostoka Rossiyskoy akademii nauk: 29-50.

Sobotka T., W. Lutz (2011). Koeffitsient summarnoy rozhdaemosti daet politikam dezorientiruyushchie signaly: ne sleduet li otkazat'sya ot ispol'zovaniya etogo pokazatelya? (translated from: Sobotka T.,W. Lutz (2010). Misleading policy messages derived from the period TFR: should we stop using it? // Comparative Population Studies. 35(3): 637-664) // Ekonomicheskiy zhurnal VSHE [Economic Journal of the Higher School of Economics]. 4: 444-471. See also : Demoscope Weekly. 495-496. URL: http://www.demoscope.ru/weekly/2012/0495/analit01.php

Wang E. (2015). Demograficheskaya politika Kitaya v nachale XXI veka [Demographic policy of China in the early twenty-first century] // Nastoyashchee i budushchee sem'i v menyayushchemsya mire [Present and future of the family in a changing world] / $\mathrm{N}$. Rimachevskaya, ed. Moscow: Ekon-Inform: 303-310.

Zhang L. (2016). DINK family: the fashion of the youth? - a cross-national comparative study // A sociological almanac. 7: 442-454. 